Research Article

\title{
Environmental Risk Assessment of Subway Station Construction to Achieve Sustainability Using the Intuitionistic Fuzzy Analytic Hierarchy Process and Set Pair Analysis
}

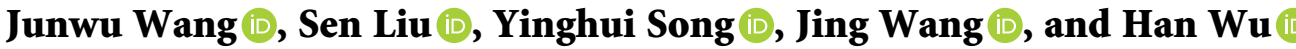 \\ School of Civil Engineering and Architecture, Wuhan University of Technology, Wuhan 430070, China \\ Correspondence should be addressed to Han Wu; wuhan20170620@163.com
}

Received 26 January 2021; Revised 25 March 2021; Accepted 17 April 2021; Published 26 April 2021

Academic Editor: Victor Shi

Copyright (c) 2021 Junwu Wang et al. This is an open access article distributed under the Creative Commons Attribution License, which permits unrestricted use, distribution, and reproduction in any medium, provided the original work is properly cited.

\begin{abstract}
Environmental risks have a significant impact on the sustainability of subway station construction projects. This paper proposes an environmental risk assessment model based on the intuitionistic fuzzy analytic hierarchy process (IFAHP) and set pair analysis (SPA) to deal with the ambiguity and uncertainty in the assessment. An index system for environmental risk assessment is established based on a literature review and the rough set method. Subsequently, the IFAHP is used to calculate the indicator weights to describe the certainty, uncertainty, and hesitation degree of expert decisions in the weighting calculation by means of affiliation, nonaffiliation, and hesitation. Finally, SPA, which can deal with the randomness, uncertainty, and ambiguity of the indicators, is used to assess environmental risk. A case study of two typical stations (Lushan Avenue Station and Huilong Road West Station) of Metro Line 11 in Chengdu, China, is conducted. The case study results are consistent with field surveys. The evaluation results of the proposed model are more objective and reasonable than those of the traditional analytic hierarchy process, the entropy weight method, fuzzy comprehensive evaluation, grey correlation analysis, and technique for order of preference by similarity to an ideal solution (TOPSIS). The research results prove the scientific validity and superiority of the proposed model.
\end{abstract}

\section{Introduction}

A subway station is a large, multilayered underground structure and an important component in subway construction projects [1]. Due to the large construction scale and open construction site, subway station engineering is susceptible to environmental influences during construction, which may affect the sustainability of subway station construction projects [2]. The environmental risks of metro station engineering are related to the external environment, such as geological conditions [3], the hydrological environment [4], and many other factors. These factors could easily lead to construction safety accidents, construction efficiency decline, and other adverse events. Then, these adverse events presumably disrupt the sustainability of subway station construction projects and cause the loss of life and property in the construction site. The research on environmental risks is an important way and guarantee to achieve the sustainability of subway station construction projects.

At present, engineering practice uses on-site investigation and verification of major hazard sources in subway station construction to identify and evaluate environmental risks. However, these qualitative and passive methods may be unable to deal with the challenges of numerous risk factors and the randomness, vagueness, and uncertainty. Therefore, to achieve sustainability of subway station construction projects, this paper proposes an environmental risk assessment of subway station engineering based on the intuitionistic fuzzy analytic hierarchy process (IFAHP) and the set pair analysis (SPA) to deal with the ambiguity and uncertainty of environmental risk assessment of subway station construction.

Scholars often assess environmental risks as part of construction risks or construction safety risks. Shen et al. [1] discussed five dimensions of environmental risks, that is, 
foundation pit construction risks, structural construction risks, ancillary facilities and equipment risks, environmental risks, and geological and natural risks. The risks of subway pit construction were assessed, but the environmental risk was considered part of the construction risk. Pan et al. [5] analyzed the main risk factors that might cause accidents in the construction of subway shield tunnels regarding human, mechanical equipment, environmental, and management factors. The definition of environmental risk was similar to that used in this study. Wu et al. [6] analyzed the influence of geological environment risk factors on the cost of the Fangshan subway line project. $\mathrm{Hu}$ and Duan [7] adopted a fuzzy evaluation method to assess and classify the risk sources for a metro tunnel crossing an existing highway; the study considered the impact of the geological environment on the construction of a metro tunnel as a construction risk. Niu et al. [8] introduced the Kent method to evaluate the safety risk in a new subway tunnel that was close to an existing tunnel. In that paper, environmental risk was a part of safety risk. Luo et al. [9] developed a safety risk assessment model using the analytic hierarchy process (AHP) and fuzzy matter-element method (FMEM). To the best of the authors' knowledge, no research has been reported to date on environmental risk assessment of subway station construction.

The weight calculation of the evaluation indicators is a key task in risk assessment, directly affecting the scientific validity of the evaluation results. Traditional methods for calculating the risk factor weights include the AHP [10-12], the Delphi method [13], and the fuzzy analytic hierarchy process (FAHP) [14, 15]. These subjective weighting methods rely heavily on the experts' empirical decisions and do not represent an accurate weighting approach. The inability to define the hesitation factor and vagueness in the expert's description regarding the importance of the indicator may be the main source of the highly subjective nature of these methods. Objective calculation methods, such as the entropy weighting method [3], are often used to calculate the weights of construction risks in metro projects. However, these objective weighting methods often have two shortcomings: they do not use expert knowledge, and the results are difficult to interpret [16]. Intuitionistic fuzzy analysis, which takes into account the subjective decisions and choices of decision-makers and the influence of the fuzzy nature of preferences on the weighting process, has been increasingly used for the weighting of indicators in recent years. Intuitionistic fuzzy analysis integrates not only expert knowledge but also minimizes subjective decisions through accurate and objective processing. Ohta et al. [17] introduced four kinds of AHP: classical AHP, FAHP, IFAHP, and hesitant fuzzy AHP (HFAHP) in the actual factory maintenance management application. It provides a reference for the application of related theories in management, engineering, and other fields of social sciences. Yu et al. [18] considered the hesitation and consistency test of the evaluation experts in the index comparison process in the index evaluation process. The use of IFAHP does not need to invite experts to repeat the score, reducing human intervention, and the evaluation process is simpler and more objective. $\mathrm{Xu}$ et al. [19] used IFAHP to comprehensively evaluate the development performance of GVCGF. The results show that the development performance of GVCGF is at a "relatively high" level. Compared with the traditional analytic hierarchy process, IFAHP effectively avoids the false expansion of the impact caused by the subjectivity of the data and the uncertainty of the evaluation.

The choice of risk assessment model is another crucial task in the environmental risk assessment of metro station construction projects. Luo et al. [9] used the FMEM to calculate the correlation between the geo-environmental risk indicators and classify the risk level of the indicators to determine the project's risk level. Since it is difficult to obtain accurate engineering data in construction engineering, Wang \& Chen [20] proposed a systematic decision support method based on a fuzzy integrated Bayesian network (FCBN), which combines the fuzzy integrated evaluation method (FCEM) and Bayesian network (BN), to analyze the safety risk of subway construction projects under uncertain conditions. Wu et al. [21] proposed a fuzzy analytic network process comprehensive evaluation (FANPCE) model for risk assessment of subway station construction. Qin et al. [22] proposed a new decision model combining an interval type2 fuzzy set and the TOPSIS method to assess the dynamic risks of metro stations. Huang et al. [23] used the AHP and grey theory to analyze construction safety risk in China's construction industry. The results of this method are better than the safety checklist method, which is one of the most commonly used methods in engineering practice but has the shortcoming of not accurately portraying the experience and decision of experts, resulting in highly subjective calculation results. Sun et al. [24] emphasized that important tools for handling uncertain and fuzzy information such as hesitant fuzzy sets should be introduced into classic evaluation methods, which can significantly improve the accuracy and reliability of traditional evaluation methods. At present, the methods of subway construction environmental risk assessment mostly use fuzzy evaluation. However, due to different risk factors in different subway projects, the risk factors are often random and complex, and the factors influencing construction risk factors have both certainty and uncertainty information. Therefore, the description of the general evaluation method is not adequate, and it is difficult to evaluate the deterministic and uncertain characteristics of the risk influencing factors comprehensively.

The SPA can accurately depict the relationship between certainty and uncertainty and provides a new method to assess the environmental risk of metro construction. The SPA has been widely applied in many fields. Wang [2] used the SPA for risk assessment of karst tunnel flooding. X. F. Chen and W. T. Chen [25] argued that most blasting safety evaluation studies only considered the vagueness of the influencing factors of blasting safety. Thus, they proposed an assessment model of blasting safety based on the SPA. Wang et al. [26] considered the uncertainty of the risks caused by subway construction to nearby buildings and proposed the use of SPA to evaluate the safety of cultural relics adjacent to subway construction. The results show that the effectiveness of the model provides decision support for controlling the risks of similar projects. 
The main contributions of this study are as follows. (1) We conduct a literature review to determine an initial and common index system for the evaluation of environmental risk in subway station construction. Subsequently, we propose an indicator system for environmental risk assessment of a typical subway station project for the first time, using the rough set method for indicator approximation. (2) An environmental risk assessment model for subway station construction based on the IFAHP and SPA is established. The certainty, uncertainty, and hesitation factor of expert decisions in the weight calculation are considered by determining the degree of affiliation, nonaffiliation, and hesitation in the IFAHP. The SPA is selected to deal with the randomness, ambiguity, and incompleteness in the environmental risk assessment of subway station construction. (3) The Lushan Avenue Station and Huilong Road West Station of the Chengdu Metro Line 11 in Chengdu, Sichuan Province, China, are selected as case studies. The results of the case studies show that the frequency of natural disasters has the largest weight (0.183) and is the most important factor affecting the environmental risk of the subway station. The Lushan Avenue Station has a risk level of $\mathrm{V}$ (extreme risk) and Huilong Road West Station has a risk level of III (moderate risk). In addition, this paper provides the measures to improve the sustainability of them, based on the calculation results of weights and environmental risks.

The remaining sections of this paper are arranged as follows. Section 2 describes the materials and methods, including the establishment of an environmental risk assessment index system for the metro station and an assessment model based on the IFAHP and the SPA. Section 3 describes the case study and provides the measures to improve the sustainability of the Lushan Avenue Station and Huilong Road West Station of Line 11 of the Chengdu Metro in China. Section 4 is a discussion of the results of different weighting methods and evaluation method calculations to highlight the superiority of the proposed models. Section 5 provides the conclusion, summarizing the findings and suggesting future research directions.

\section{Materials and Methods}

\subsection{Environmental Risk Assessment Index System of Subway Station Engineering}

2.1.1. Preliminary Selection of Environmental Risk Assessment Index for Subway Station Engineering. The establishment of an evaluation index system is the basis for an environmental risk assessment of subway station construction. The scientific validity and rationality of the index system affect the accuracy of the evaluation results. At present, there is little research on the environmental risk of subway station construction and a lack of a unified and general environmental risk assessment index system. Therefore, we conduct a literature review to obtain information on the construction risks, environmental risks, and the sustainable development of subway station engineering. Subsequently, an initial index system of environmental risk assessment of subway station engineering is established, as shown in Table 1.

2.1.2. Index System Establishment Based on the Rough Set Method. The index system in Table 1 is based on subway construction safety risk and environmental risk in other disciplines; thus, it may not be suitable for subway station engineering. We selected 38 typical subway station projects in China for index screening and developed an index system conforming to the construction characteristics of subway station projects. The 38 subway stations are 17 stations of the Chengdu Metro Line 11, 9 stations of the Wuhan Metro Line 8 , and 12 stations of the Wuhan Metro Line 21.

Commonly used index screening methods are divided into two categories: qualitative screening [34, 35] and quantitative screening [36-38]. Qualitative screening relies entirely on expert experience, resulting in highly subjective results. Quantitative screening does not consider expert opinion and experience, and the screening results are difficult to interpret. The rough set does not only avoid the lack of qualitative screening relying on expert experience but also considers the practical experience of industry experts. Therefore, we use the rough set method to screen the environmental risk indices of subway station engineering.

We selected 20 experienced experts who worked in the subway industry for many years. The details of the selected experts are shown in Figures 1-3. Twenty experts scored the importance degree of the indices in Table 1 and reduced the number of indices using Rosetta, a commonly used rough set software.

Rough sets theory is a mathematical method proposed by Polish scientist Z. Pawlak to deal with inaccurate, uncertain, and incomplete data [39]. In the process of rough set reduction, the relationship between evaluation indicators and decision indicators can be established according to methods such as self-information and mutual information, so as to determine the importance of conditional attributes and calculate weights [39]. The basic principle of the rough set method and the index reduction process using the Rosetta software has been described in [39]. Finally, seven indicators were selected to comprise the evaluation index system of the subway station environment. The interpretation of the indices is shown in Table 2.

It should be emphasized that the index system in Table 3 was designed for the 38 typical metro station projects in China. The proposed method can be used to obtain a targeted index system using the information in Table 1 to conduct an environmental risk assessment of other subway station projects.

2.1.3. Environmental Risk Assessment Standards for Metro Station Construction. The environmental risk level is divided into five levels, according to the needs of subway station project management: no risk (I), low risk (II), medium risk (III), high risk (IV), and extreme risk (V). No risk (I) means that the environmental risk is negligible, the sustainability is perfect, and no measures are needed. Low risk (II) means that the potential adverse impacts of 
TABLE 1: Initial index system of environmental risk assessment for subway station engineering.

\begin{tabular}{lcc}
\hline Indicator & References & Screening results \\
\hline Harsh hydrological conditions & {$[27]$} & Retained \\
Rainfall & {$[28]$} & Deleted \\
Complex groundwater conditions & {$[29]$} & Deleted \\
Frequency of geological disasters & {$[30]$} & Deleted \\
Adverse geological conditions & {$[31]$} & Retained \\
Adverse geomorphological conditions & {$[27]$} & Retained \\
Distance from a river & {$[31]$} & Deleted \\
Stability of foundation of nearby buildings & {$[20]$} & Deleted \\
Number of obstacles in underground construction & {$[32]$} & Deleted \\
Frequency of natural disasters & {$[1]$} & Retained \\
Frequency of earthquake disasters & {$[1]$} & Deleted \\
Frequency of flood disasters & {$[1]$} & Deleted \\
Frequency of severe weather & {$[33]$} & Retained \\
Abnormal load & {$[21]$} & Deleted \\
Confined construction space & {$[21]$} & Deleted \\
Density of underground pipelines & {$[30]$} & Retained \\
Layout of pipelines & {$[20]$} & Deleted \\
Surrounding roads and traffic conditions & {$[5]$} & Deleted \\
Density of surrounding buildings & {$[1]$} & Retained \\
\hline
\end{tabular}

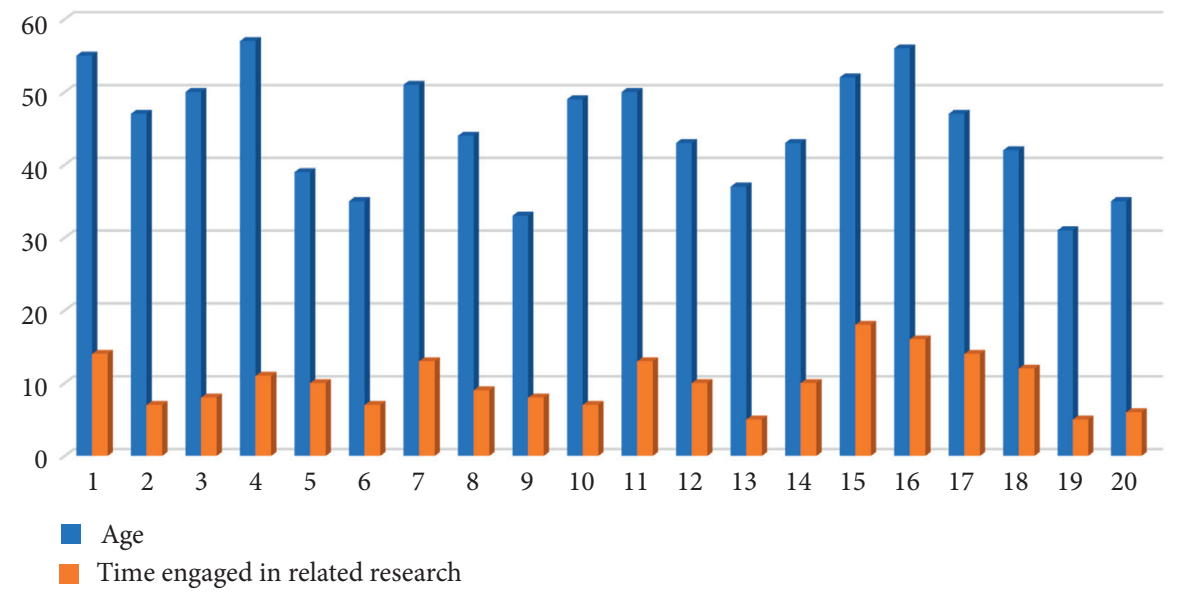

Figure 1: Distribution of age and working years of review experts participating in this project.

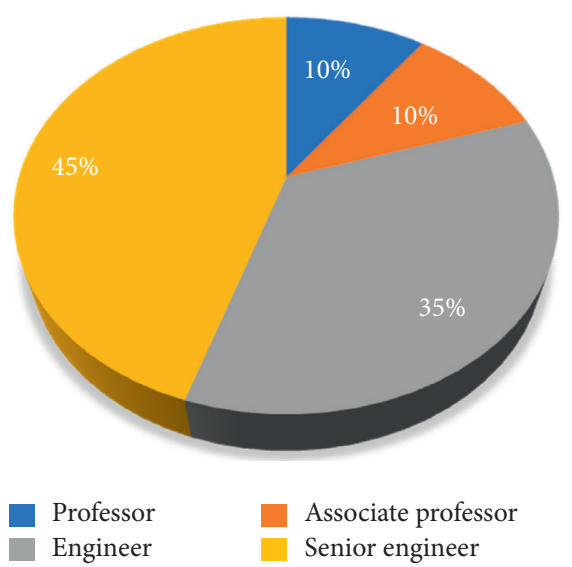

FIGURE 2: Distribution of expert title. 


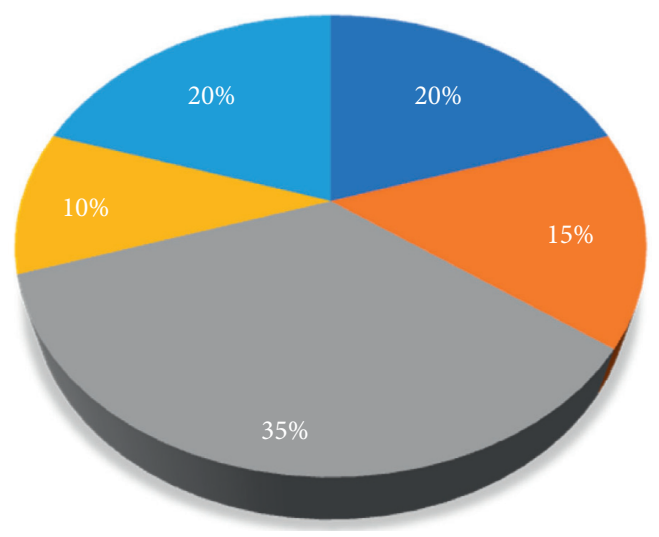

Wuhan University of Technology

Chengdu Rail Transit Group Co., Ltd.

China Construction Third Engineering Bureau Group Co., Ltd.

Hubei Road and Bridge Group Co., Ltd.

Wuhan Metro Group Co., Ltd.

FIGURE 3: Distribution of expert work units.

TABLE 2: Classification standard for environmental risk assessment.

\begin{tabular}{lccccccc}
\hline Index & No. & Unit & I & II & III & IV \\
\hline Harsh hydrological conditions & E1 & - & No $[0,20)$ & Few $[20,40)$ & Moderate [40,60) & Many [60, 80) & Excess [80, 100] \\
Adverse geological conditions & E2 & - & No $[0,20)$ & Few [20,40) & Moderate [40,60) & Many [60, 80) & Excess [80, 100] \\
Adverse geomorphological conditions & E3 & - & No $[0,20)$ & Few $[20,40)$ & Moderate [40,60) & Many [60, 80) & Excess [80, 100] \\
Frequency of natural disasters & E4 & times/year & {$[0,0.1)$} & {$[0.1,0.5)$} & {$[0.5,1)$} & {$[1,2)$} & {$[2,+\infty)$} \\
Frequency of severe weather & E5 times/year & {$[0,3)$} & {$[3,6)$} & {$[6,12)$} & {$[12,24)$} & {$[24,+\infty)$} \\
Density of underground pipelines & E6 & $\mathrm{km} / \mathrm{km}^{2}$ & {$[0,1)$} & {$[1,2)$} & {$[2,4)$} & {$[4,8)$} & {$[8,+\infty)$} \\
Density of surrounding buildings & E7 & $/ \mathrm{km}^{2}$ & {$[0,1)$} & {$[1,2)$} & {$[2,4)$} & {$[4,8)$} & {$[8,+\infty)$} \\
\hline
\end{tabular}

environmental risk are acceptable, but project managers should check the implementation of existing environmental management measures in order to maintain the sustainability. Medium risk (III) means that project managers need to decide whether to take further environmental risk response measures to maintain the sustainability. High risk (IV) means that environmental risks are high and the sustainability has been destroyed. If risk is IV, the project management personnel are advised to stop the construction work and take targeted risk response measures, according to the environmental risk assessment results. Extreme risk (V) means that the adverse impact of environmental risk factors is unacceptable. Project management personnel must immediately stop the construction of subway station engineering and take decisive measures to reduce the level of environmental risk.

The opinions of 20 experts were used in accordance with China's national codes (Code for Design of Metro, GB 50157-2013; Technical Guidelines for Environmental Risk Assessment on Projects, HJ 169-2018; standard for sustainability assessment of building project, JGJ/T 222-2011) to develop a classification standard for environmental risk assessment for subway station construction, considering the 38 subway stations (Table 2). E1, E2, and E3 are qualitative indicators, and the risk level description is divided into qualitative descriptions and a quantitative score range. For example, the "no risk" risk level of E1 is described as "no [0, 20)," where "no" is the qualitative description, and $[0,20)$ is the quantitative score range. If the experts have determined that the risk level E1 is none from their own experience, it means that the index score is between 0 and 20. It must be pointed out that the upper limit of the quantitative indices E4, E5, E6, and E7 has not been determined. Therefore, the upper limit of these indicators is " $+\infty$ " in Table 4 . When these indicators are used for a case analysis, the upper limit value should be in line with the needs of project management of metro station engineering.

\subsection{Environmental Risk Assessment Model of Subway Station Engineering}

2.2.1. Introduction to the Intuitionistic Fuzzy Analytic Hierarchy Process. The concept of intuitionistic fuzzy sets was proposed by Bulgarian scholar Atanassov in 1983 [40]; it is an extension of the traditional fuzzy set theory proposed by Zadeh [41]. The traditional fuzzy sets, which only consider the membership, are extended to intuitionistic fuzzy sets that 
TABLE 3: Index system and interpretation of environmental risk assessment for metro stations.

\begin{tabular}{|c|c|c|}
\hline Indicator & No. & Indicator interpretation \\
\hline Harsh hydrological conditions & E1 & $\begin{array}{l}\text { Metro stations are usually constructed underground and are substantially affected by hydrological } \\
\text { conditions. When the groundwater table is high, measures are required to deal with water inflow, } \\
\text { which increases the structural requirements and prolongs the construction period. After lowering } \\
\text { the groundwater level, uneven settlement of the surrounding buildings may occur, and the main } \\
\text { structure of the station may experience "floating." Harsh hydrological conditions also adversely } \\
\text { affect the stability of the foundation pit support. }\end{array}$ \\
\hline Adverse geological conditions & E2 & $\begin{array}{l}\text { Adverse geological conditions will increase the difficulty of subway station excavation, increase the } \\
\text { cost, and prolong the construction period. The worse the geological environment, the more } \\
\text { complex the foundation pit support has to be, and the worse the stability is. The supporting } \\
\text { structure may not adapt adequately to adverse geological conditions, resulting in geological } \\
\text { disasters, such as landslides. }\end{array}$ \\
\hline $\begin{array}{l}\text { Adverse geomorphological } \\
\text { conditions }\end{array}$ & E3 & $\begin{array}{l}\text { Adverse geomorphic conditions may cause landslides, waterlogging, and other natural disasters. If } \\
\text { the stability of the deep foundation pit of the station project is poor, additional measures are } \\
\text { required during project construction, affecting the project cost and the construction period. }\end{array}$ \\
\hline Frequency of natural disasters & E4 & $\begin{array}{l}\text { Typhoons, earthquakes, tsunamis, landslides, mudslides, and other natural disasters may have a } \\
\text { devastating impact on the subway station project, and people, materials, and equipment at the } \\
\text { construction site may be damaged. }\end{array}$ \\
\hline Frequency of severe weather & E5 & $\begin{array}{l}\text { Low or high temperatures, heavy snow, strong wind (blowing sand), heavy rainfall, and other severe } \\
\text { weather does not only reduce the safety of construction workers but also causes accidents and } \\
\text { adversely affects the construction cost and construction period. }\end{array}$ \\
\hline $\begin{array}{l}\text { Density of underground } \\
\text { pipelines }\end{array}$ & E6 & $\begin{array}{l}\text { Underground pipeline protection is an important aspect of subway station construction. The } \\
\text { denser the underground pipelines are, the more difficult the construction is, and the more likely it is } \\
\text { that the construction period and cost are affected. Underground pipelines are often municipal } \\
\text { pipelines. Once damaged, people, materials, and equipment at the construction site may be } \\
\text { seriously damaged, and the daily life of residents may be affected. }\end{array}$ \\
\hline $\begin{array}{l}\text { Density of surrounding } \\
\text { buildings }\end{array}$ & E7 & $\begin{array}{l}\text { The greater the density of buildings around the station, the greater the difficulty of construction is, } \\
\text { and the more likely it is that the construction period and cost will be affected. The greater the } \\
\text { density of the buildings around the foundation pit, the more complex the supporting structure of } \\
\text { the foundation pit has to be, and the worse the stability is. }\end{array}$ \\
\hline
\end{tabular}

consider membership, nonmembership, and hesitation. Therefore, the intuitionistic fuzzy set method is more flexible and practical than traditional fuzzy sets in dealing with fuzziness and uncertainty. Xu nd Liao developed the IFAHP based on Zadeh's fuzzy set theory [42].

The basic steps of the IFAHP to calculate the weight of the environmental risk assessment indices of subway station are as follows.

Step 1. Construct intuitionistic fuzzy decision matrix

It is necessary to establish the intuitionistic fuzzy decision matrix to describe the information comprehensively and objectively:

$$
\mathbf{Z}=\left(z_{i j}\right)_{n \times n},
$$

where $z_{i j}=\left(\mu_{i j}, v_{i j}\right), i, j=1,2, \ldots, n$ represents the evaluation result of the decision-maker after comparing the importance of the two indicators. $\mu_{i j}$ denotes the degree of membership, which is the degree of importance of the $i$ index over the $j$ index. $v_{i j}$ represents the degree of hesitation $\pi_{i j}=1-\mu_{i j}-v_{i j}$. The evaluation scale used in [43] is used in this study to quantify the importance of the evaluation indicators, as shown in Table 4.

\section{Step 2. Consistency test.}

In the IFAHP, it is necessary to test the consistency of the intuitionistic decision matrix to prevent unreliable results or errors. The consistency of the intuitionistic decision matrix is defined as [42]

$$
\bar{Z}=\left(\bar{z}_{i j}\right)_{n \times n}
$$

when $j>i+1, \bar{z}_{i j}=\left(\bar{\mu}_{i j}, \bar{v}_{i j}\right)$. Consider

$\bar{\mu}_{i j}=\sqrt[j-i-1]{\frac{\prod_{t=i+1}^{j-1} \mu_{i t} \mu_{t j}}{\sqrt[j-i-1]{\prod_{t=i+1}^{j-1} \mu_{i t} \mu_{t j} \sqrt[j-i-1]{\prod_{t=i+1}^{j-1}\left(1-\mu_{i t}\right)\left(1-\mu_{t j}\right),}}}}$

$$
\bar{v}_{i j}=\sqrt[j-i-1]{\frac{\prod_{t=i+1}^{j-1} v_{i t} v_{t j}}{\sqrt[j-i-1]{\prod_{t=i+1}^{j-1} v_{i t} v_{t j} \sqrt[j-i-1]{\prod_{t=i+1}^{j-1}\left(1-v_{i t}\right)\left(1-v_{t j}\right)}}}}
$$


TABLE 4: The relationship between the evaluation results and the intuitionistic fuzzy number.

\begin{tabular}{lccr}
\hline Evaluation result & Intuitionistic fuzzy number & Evaluation result & Intuitionistic fuzzy number \\
\hline Extremely important & $(0.90,0.10)$ & Less important & $(0.40,0.45)$ \\
Very important & $(0.80,0.15)$ & Unimportant & $(0.30,0.60)$ \\
Important & $(0.70,0.20)$ & Very unimportant & $(0.20,0.75)$ \\
More important & $(0.60,0.25)$ & Extremely unimportant & $(0.10,0.90)$ \\
Equally important & $(0.50,0.30)$ & - & - \\
\hline
\end{tabular}

when $j=i+1$ or $j=i, \bar{z}_{i j}=z_{i j}$. When $j<i, \bar{z}_{i j}=\left(\bar{v}_{j i}, \bar{v}_{j i}\right)$.

If the distance measure $d$ between $\mathbf{Z}$ and $\bar{Z}$ satisfies $d(\mathbf{Z}, \bar{Z})<\tau$, the intuitionistic decision matrix meets the consistency requirement. $\tau$ is the consistency index threshold, and the value used here is 0.1 .

$$
d(\bar{Z}, \mathbf{Z})=\frac{1}{2(n-1)(n-2)} \sum_{i=1}^{n} \sum_{j=1}^{n}\left(\left|\bar{\mu}_{i j}-\mu_{i j}\right|+\left|\bar{v}_{i j}-v_{i j}\right|+\left|\bar{\pi}_{i j}-\pi_{i j}\right|\right) .
$$

In contrast, when $(\bar{Z}, t Z) \geq \tau$, it is assumed that the consistency of the intuitionistic decision matrix has to be adjusted. The iteration parameter $\sigma$ is input, and $\sigma$ is adjusted to change the intuitionistic fuzzy decision matrix until it passes the consistency test. The range of the parameter $\sigma$ in this study is $\sigma \in[0,1]$, and an iterative test is performed starting with 1 with a step length of -0.01 . The conversion process is as follows [37]:

$$
\begin{aligned}
\widetilde{\mu}_{i j} & =\frac{\left(\mu_{i j}\right)^{1-\sigma}\left(\bar{\mu}_{i j}\right)^{\sigma}}{\left(\mu_{i j}\right)^{1-\sigma}\left(\bar{\mu}_{i j}\right)^{\sigma}+\left(1-\mu_{i j}\right)^{1-\sigma}\left(1-\bar{\mu}_{i j}\right)^{\sigma}}, \\
\widetilde{v}_{i j} & =\frac{\left(v_{i j}\right)^{1-\sigma}\left(\bar{v}_{i j}\right)^{\sigma}}{\left(v_{i j}\right)^{1-\sigma}\left(\bar{v}_{i j}\right)^{\sigma}+\left(1-v_{i j}\right)^{1-\sigma}\left(1-\bar{v}_{i j}\right)^{\sigma}}, \\
d(\widetilde{Z}, \mathbf{Z}) & =\frac{1}{2(n-1)(n-2)} \sum_{i=1}^{n} \sum_{j=1}^{n}\left(\left|\widetilde{\mu}_{i j}-\mu_{i j}\right|+\left|\widetilde{v}_{i j}-v_{i j}\right|+\left|\widetilde{\pi}_{i j}-\pi_{i j}\right|\right) .
\end{aligned}
$$

In this step, the IFAHP shows another advantage. When the consistency test fails, in the traditional AHP or the FAHP, the expert opinions have to be obtained again, and the test has to be repeated. However, this is not required in the IFAHP, and the parameters in the consistency test can be adjusted.

Step 3. Determination of weights.

After obtaining the matrix that satisfies the consistency test, the matrix is simplified using

$$
\omega_{i}=\left(\frac{\sum_{j=1}^{n} \bar{\mu}_{i j}}{\sum_{i=1}^{n} \sum_{j=1}^{n}\left(1-\bar{v}_{i j}\right)}, 1-\frac{\sum_{j=1}^{n}\left(1-\bar{v}_{i j}\right)}{\sum_{i=1}^{n} \sum_{j=1}^{n} \bar{\mu}_{i j}}\right) \text {. }
$$

We calculate the score of the index weight:

$$
H\left(\omega_{i}\right)=\frac{1-v_{i}}{1+\pi_{i}}
$$

After normalization, the index weight is obtained:

$$
\sigma_{i}=\frac{H\left(\omega_{i}\right)}{\sum_{j=1}^{n} H\left(\omega_{i}\right)} \text {. }
$$

2.2.2. Introduction to Set Pair Analysis. SPA is a quantitative analysis theory that considers certainty and uncertainty as an integrated system and describes them as identity, discrepancy, and contrary relationships. SPA was proposed by the Chinese scholar Zhao [44]. Certainty includes identity and contrary relationships, whereas uncertainty only refers to the discrepancy relationship.

In the SPA, the connection degree is used to describe the certainty and uncertainty of the system and their mutual transformation rules. The expression of the connection degree is [44]

$$
\mu=a+b i+c j
$$


where $a, b$, and $c$ are the identity degree, discrepancy degree, and contrary degree of the set pair under certain conditions background. $i$ and $j$ are the uncertainty coefficient of the discrepancy term and the uncertainty coefficient of the contradictory term, respectively.

Each index and the risk level standard constitute a set pair, and the connection degree between the actual state value of each index and the risk level standard is calculated. Considering the index weight, (12) can be expressed as follows:

$$
\mu=\sum_{l=1}^{m} \omega_{l} a_{l}+\sum_{l=1}^{m} \omega_{l} b_{l, 1} i_{1}+\cdots+\sum_{l=1}^{m} \omega_{l} b_{l, K-2} i_{K-2}+\sum_{l=1}^{m} \omega_{l} c_{l} j,
$$

where $\omega_{m}$ is the index $m(m=1,2, \ldots, n)$.

The degree of connection between the index $x_{l}$, which should be as small as possible, and the index level standard is [45]

$$
\mu_{l}=\left\{\begin{array}{l}
1+0 i_{1}+0 i_{2}+\cdots+0 i_{k-2}+0 j, \quad x_{l} \leq s_{1}, \\
\frac{s_{1}+s_{2}-2 x_{l}}{s_{2}-s_{1}}+\frac{2 x_{l}-s_{1}}{s_{2}-s_{1}} i_{1}+0 i_{2}+\cdots+0 i_{K-2}+0 j, \quad s_{1}<x_{l} \leq \frac{s_{1}+s_{2}}{2}, \\
0+\frac{s_{2}+s_{3}-2 x_{l}}{s_{3}-s_{1}} i_{1}+\frac{2 x_{l}-s_{1}-s_{2}}{s_{3}-s_{1}} i_{2}+\cdots+0 i_{K-2}+0 j, \quad \frac{s_{1}+s_{2}}{2}<x_{l} \leq \frac{s_{2}+s_{3}}{2}, \\
\vdots \quad i_{K-1}, \quad \frac{s_{K-2}+s_{K-1}}{2}<x_{l} \leq s_{K-1}, \\
0+0 i_{1}+0 i_{2}+\cdots+\frac{s_{K-1}-2 x_{l}}{s_{K-1}-s_{K-2}} i_{K-2}+\frac{2 x_{l}-s_{K-2}-s_{K-1}}{s_{K-1}-s_{K-2}} j, \\
0+0 i_{1}+0 i_{2}+\cdots+0 i_{K-2}+1 j, \quad x_{l}>s_{K-1},
\end{array}\right.
$$

where $s_{1} \leq s_{2} \leq \cdots \leq s_{K-1} \leq s_{K}$.

The degree of connection between the index $x_{l}$, which should be as large as possible, and the index level standard is [45]

$$
\mu_{l}=\left\{\begin{array}{l}
1+0 i_{1}+0 i_{2}+\cdots+0 i_{k-2}+0 j, \quad x_{l} \geq s_{1}, \\
\frac{2 x_{l}-s_{1}-s_{2}}{s_{1}-s_{2}}+\frac{2 s_{1}-2 x_{l}}{s_{1}-s_{2}} i_{1}+0 i_{2}+\cdots+0 i_{K-2}+0 j, \quad \frac{s_{1}+s_{2}}{2} \leq x_{l}<s_{1}, \\
0+\frac{2 x_{l}-s_{2}-s_{3}}{s_{1}-s_{3}} i_{1}+\frac{s_{1}+s_{2}-2 x_{l}}{s_{1}-s_{3}} i_{2}+\cdots+0 i_{K-2}+0 j, \quad \frac{s_{2}+s_{3}}{2} \leq x_{l}<\frac{s_{1}+s_{2}}{2} \\
\vdots \quad x_{K-2}-s_{K-1} i_{K-2}+\frac{s_{K-2}+s_{K-1}-2 x_{l}}{s_{K-2}-s_{K-1}} j, \quad s_{K-1} \leq x_{l}<\frac{s_{K-2}+s_{K-1}}{2} \\
0+0 i_{1}+0 i_{2}+\cdots+\frac{2 x_{l}-2 s_{K-1}}{s_{K-2}} \\
0+0 i_{1}+0 i_{2}+\cdots+0 i_{K-2}+1 j, \quad x_{l}<s_{K-1},
\end{array}\right.
$$

where $s_{1} \geq s_{2} \geq \cdots \geq s_{K-1} \geq s_{K}$.

The confidence degree is used to evaluate the risk level of each factor.

$$
h_{k}=\left(f_{1}+f_{2}+\cdots+f_{k}\right)>\lambda \text {, }
$$

where $\quad f_{1}=\sum_{l=1}^{m} \omega_{l} a_{l}, f_{2}=\sum_{l=1}^{m} \omega_{l} \quad b_{l, 1}, f_{3}=\sum_{l=1}^{m} \omega_{l} b_{l, 2}$, $\ldots, f_{k-1}=\sum_{l=1}^{m} \omega_{l} b_{l, K-2}, f_{k}=\sum_{l=1}^{m} \omega_{l} c_{l}$.

$\lambda$ is the confidence level, which is generally [0.50, 0.70]. The larger the value is, the more conservative the result is. 
2.3. Environmental Risk Assessment Model of Subway Station Engineering Based on the IFAHP and SPA. The flowchart of the environmental risk assessment of subway station engineering is shown in Figure 4. The detailed steps of the environmental risk assessment model are as follows.

Step 1. Field investigations and expert interviews are used to determine the indicators of the index system and their relative importance. According to the relation in Table 5, the intuitionistic fuzzy decision matrix $\mathbf{Z}=$ $\left(z_{i j}\right)_{n \times n}$ is obtained.

Step 2. The consistency of the intuitionistic decision matrix $\mathbf{Z}$ is tested. After the consistency test and adjustment, a satisfactory consistency matrix is obtained. Using (9)-(11), the weights of the indices $\mathbf{W}=\left(\sigma_{1}, \sigma_{2}, \ldots, \sigma_{n}\right)$ are obtained.

Step 3. The measured values of the sample evaluation indices are recorded as set $\mathbf{A}$, and the corresponding evaluation criteria are recorded as set $\mathbf{B}$. Sets $\mathbf{A}$ and $\mathbf{B}$ form a set pair $\mathbf{H}(\mathbf{A}, \mathbf{B})$. For example, (13) uses the fiveelement connection degree $\mu$ to describe the relationship between the set pairs.

Step 4. The score of each rating index is used in (14) and (15) to determine the connection degree of a single index.

Step 5. We obtain the connection degree of the index grade standard and index weight vector $\mathbf{W}=\left(\sigma_{1}, \sigma_{2}, \ldots, \sigma_{n}\right)$ and calculate the overall connection degree.

Step 6. According to (16), the environmental risk level of the subway station project is determined using the confidence degree.

\section{Case Study}

3.1. Case Background and Data Sources. The Chengdu Metro Line 11 is located in Chengdu, Sichuan Province, China. It spans the High-Tech Zone, the Tianfu New District, and the Shuangliu District in Chengdu. The project is $22.0 \mathrm{~km}$ long, with a total investment of about 16.5 billion RMB and 17 new subway stations. Chengdu is close to the active seismic zone of the Longmen Mountains, where seismic activities of different levels occur frequently. The terrain along the Chengdu Metro Line 11 is mostly shallow and hilly, which complicates the construction. Chengdu has a subtropical monsoon climate with abundant rainfall and a low number of sunshine hours, resulting in abundant groundwater. According to the Chengdu Metropolis Almanac, floods and droughts are frequent in Chengdu.

Lushan Avenue Station is an underground two-story frame structure and it uses an underground two-story island platform. The standard section width is $22.5 \mathrm{~m}$, the station length is $260.900 \mathrm{~m}$, and the total construction area is $15153 \mathrm{~m}^{2}$. The station is located at the intersection of planned Zhongbai Avenue and Lushan Avenue and is arranged along the north-south direction of Zhongbai Avenue. It is the interchange station between Metro Line 11 and the planned Metro Line 14. There are Wan'an Town
Heyun Community and Chengfeng Driving School to the northeast, Donglin Spring Phase II community to the northwest, Yunxi Terrace of Lushan International Community to the southwest, and China Mobile to the southeast. The enclosure structure of the station adopts the form of bored piles with internal supports.

Huilong Road West Station also adopts an underground two-story island platform. The total length of the station is $511.55 \mathrm{~m}$, the total width of the standard section is $21.10 \mathrm{~m}$, the effective platform length is $186 \mathrm{~m}$, and the total construction area of the station is $27296.22 \mathrm{~m}^{2}$. Huilong Road West Station is adjacent to the Huilong Parking Lot of Line 5 and is arranged along the east-west direction on the south side of the planned Sanchahu Expressway. The planned road has not been implemented. The station crosses the Qinglan Gully. The surrounding area of the station is mostly farmland and wasteland. There is a driving school on the northwest side of the station and the parking lot of Line 5 on the south side. The existing roads are Shuanghuang Road and Langou Road. The retaining structure of the station adopts the form of bored piles with internal support and the form of slope excavation with soil nail wall spray anchor.

We use Lushan Avenue Station and Huilong Road West Station as a case study. The two stations have the following characteristics, which was the reason for their selection.

(1) Lushan Avenue station is surrounded by a suburban development zone with complex underground pipelines. Suburban rural area of Chengdu is around Huilong Road West Station. The common surrounding environments of subway station construction are included in these two stations.

(2) The construction company for the Huilong Road West Station was China Construction Third Bureau Infrastructure Construction Investment Co., Ltd. The construction company for the Lushan Avenue station was China Construction Railway Investment and Construction Group Co., Ltd. These two construction units include almost all construction units of the Chengdu Metro Line 11. In addition, the management level and technical level of these construction enterprises are quite different.

(3) The geological conditions of Lushan Avenue Station and Huilong Road West Station are different and include typical geological conditions of subway stations in Chengdu.

The detailed information on the Chengdu Metro Line 11 and the Lushan Avenue and Huilong Road West stations was compiled and provided to the scoring experts. The details of the 20 experts invited to participate in the interviews are shown in Table 3. According to the risk classification criteria and their professional experience, the experts scored the harsh hydrological conditions, adverse geological conditions, and adverse geomorphological conditions from $[0,100]$. The average of the scores was used as the final score of the indicators.

The rest are quantitative indicators, and the data were obtained from measurements performed by professional 


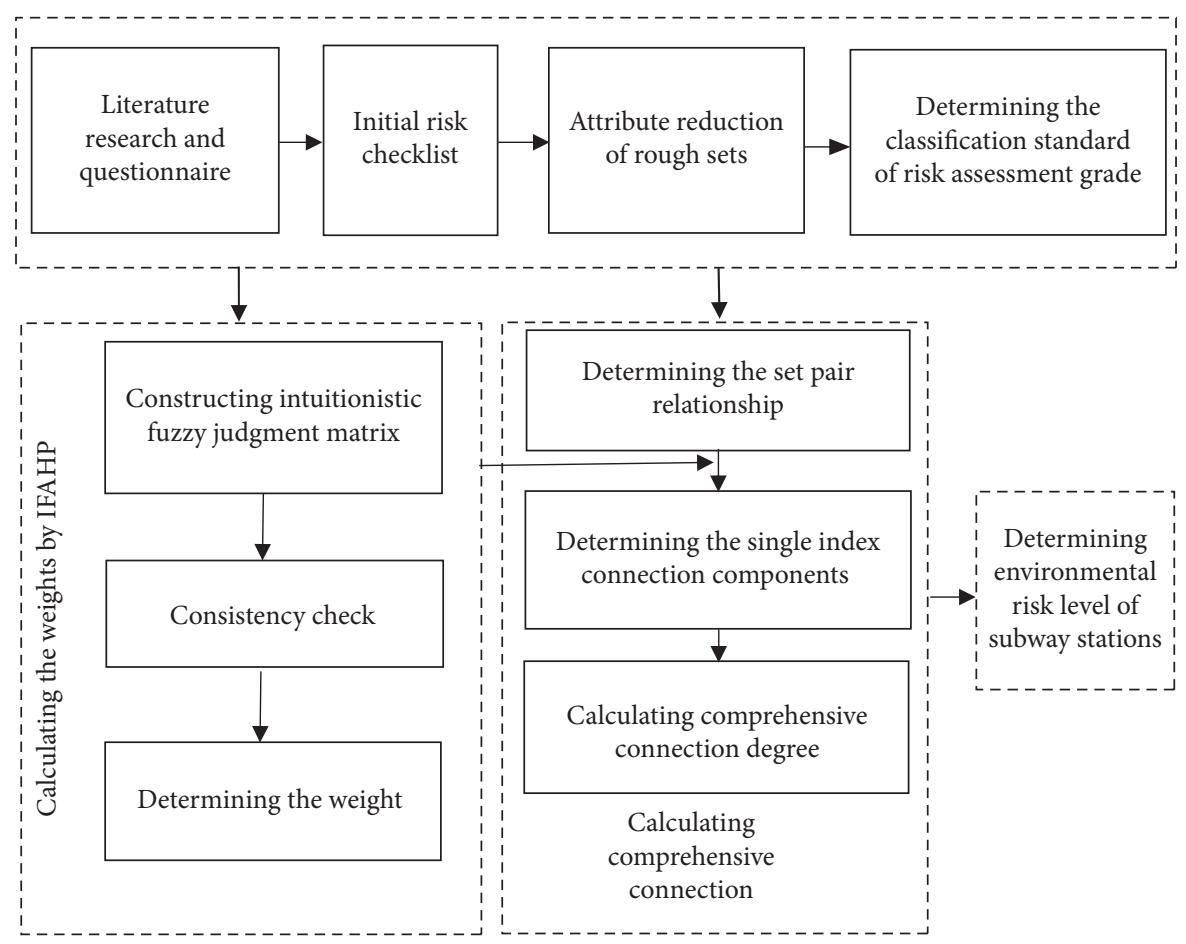

FigURE 4: Flowchart of environmental risk assessment for subway station construction.

TABLE 5: Comparative results of the importance of the evaluation indicators.

\begin{tabular}{lcccccrr}
\hline Indicator & E1 & E2 & E3 & E4 & E5 & E6 & E7 \\
\hline E1 & $(0.50,0.30)$ & $(0.40,0.45)$ & $(0.20,0.75)$ & $(0.20,0.75)$ & $(0.30,0.60)$ & $(0.40,0.45)$ & $(0.70,0.20)$ \\
E2 & $(0.60,0.25)$ & $(0.50,0.30)$ & $(0.30,0.60)$ & $(0.30,0.60)$ & $(0.40,0.45)$ & $(0.60,0.25)$ & $(0.70,0.20)$ \\
E3 & $(0.80,0.15)$ & $(0.70,0.20)$ & $(0.50,0.30)$ & $(0.40,0.45)$ & $(0.60,0.25)$ & $(0.70,0.20)$ & $(0.90,0.10)$ \\
E4 & $(0.80,0.15)$ & $(0.70,0.20)$ & $(0.60,0.25)$ & $(0.50,0.30)$ & $(0.60,0.25)$ & $(0.70,0.20)$ & $(0.90,0.10)$ \\
E5 & $(0.70,0.20)$ & $(0.60,0.25)$ & $(0.40,0.45)$ & $(0.40,0.45)$ & $(0.50,0.30)$ & $(0.60,0.25)$ & $(0.80,0.15)$ \\
E6 & $(0.60,0.25)$ & $(0.40,0.45)$ & $(0.30,0.60)$ & $(0.30,0.60)$ & $(0.40,0.45)$ & $(0.50,0.30)$ & $(0.70,0.20)$ \\
E7 & $(0.30,0.60)$ & $(0.30,0.60)$ & $(0.10,0.90)$ & $(0.10,0.90)$ & $(0.20,0.75)$ & $(0.30,0.60)$ & $(0.50,0.30)$ \\
\hline
\end{tabular}

engineers at the project site. The frequency of natural disasters is the average number of natural disasters per year in the Chengdu area according to the national natural disaster statistics released by the Ministry of Emergency Management of the People's Republic of China in the past 10 years. The frequency of severe weather events is the average number of severe weather occurrences per year for the past 5 years as published on the website of the Chengdu Meteorological Bureau. The density of underground pipelines was determined by the available data from Lushan Avenue Station and Huilong Road West Station and survey data per square kilometer of the construction area. Density of surrounding buildings is the average number of buildings per square kilometer within $500 \mathrm{~m}$ of the construction area of Lushan Avenue Station and Huilong Road West Station. The scores of all indicators were averaged. It is important to note that the upper limits of the quantitative indicators E4, E5, E6, and E7 are 20,240,80, and 80, respectively, as required by the project management practices for the Foothill Avenue Station and the Huilong Road West Station.
The scores of the indicators for Lushan Avenue Station and Huilong Road West Station are shown in Table 6.

3.2. Indicator Weights. The results of the comparison of the importance of the evaluation indicators are shown in Table 5 . These results are based on the data in Table 4, previous studies on environmental risk assessment in metro station projects, and the data from the questionnaire data on the importance of all the indicators in Table 2.

The consistency test results (see (2)-(5)) indicate that the distance measure $d(\bar{Z}, t Z)=0.172>0.1$ between $\mathbf{Z}$ and $\overline{\mathbf{Z}}$ does not meet the requirement of $\mathbf{Z}$ of the intuitionistic decision matrix. Thus, the results are corrected by (6)-(8). When $\delta=0.56, d(\widetilde{Z}, \mathbf{Z})=0.0987<0.1$. The intuitionistic decision matrix passes the one-time test; the importance levels of the corrected evaluation indicators and the weighting results of the indicators are shown in Table 7.

The maximum weight of the E4 (frequency of natural disasters) is 0.183; thus, E4 is the most important factor 
TABLE 6: The results of seven indicators' five-element contact numbers by the SPA.

\begin{tabular}{lccccccccccc}
\hline \multirow{2}{*}{ Index } & \multicolumn{4}{c}{ Lushan avenue station } & \multicolumn{4}{c}{ Huilong road west station } \\
& Score & $\mathrm{a}$ & $\mathrm{b} 1$ & $\mathrm{~b} 2$ & $\mathrm{~b} 3$ & $\mathrm{c}$ & Score & $\mathrm{a}$ & $\mathrm{b} 1$ & $\mathrm{~b} 2$ & $\mathrm{~b} 3$ \\
\hline E1 & 76.5 & 0 & 0 & 0 & 0.35 & 0.65 & 71.5 & 0 & 0 & 0 & 0.85 \\
E2 & 86.5 & 0 & 0 & 0 & 0 & 1 & 84.5 & 0 & 0 & 0.15 \\
E3 & 78.5 & 0 & 0 & 0 & 0.15 & 0.85 & 25 & 0.5 & 0.5 & 0 & 0 \\
E4 & 0.625 & 0 & 0.28 & 0.72 & 0 & 0 & 0.625 & 0 & 0.28 & 0.72 & 0 \\
E5 & 5.7 & 0 & 0.6 & 0.4 & 0 & 0 & 5.7 & 0 & 0.6 & 0.4 & 0 \\
E6 & 1.5 & 0 & 1 & 0 & 0 & 0 & 0 & 1 & 0 & 0 & 0 \\
E7 & 7 & 0 & 0 & 0 & 0.5 & 0.5 & 0 & 1 & 0 & 0 & 0 \\
\hline
\end{tabular}

TABLE 7: The importance levels of the corrected evaluation indicators and weighting results.

\begin{tabular}{lccccccc}
\hline Indicator & E1 & E2 & E3 & E4 & E5 & E6 & E7 \\
\hline E1 & $(0.500,0.300)$ & $(0.400,0.450)$ & $(0.212,0.645)$ & $(0.188,0.688)$ & $(0.291,0.526)$ & $(0.403,0.390)$ & $(0.678,0.190)$ \\
E2 & $(0.517,0.329)$ & $(0.500,0.300)$ & $(0.300,0.600)$ & $(0.255,0.573)$ & $(0.395,0.383)$ & $(0.544,0.251)$ & $(0.743,0.151)$ \\
E3 & $(0.673,0.187)$ & $(0.646,0.253)$ & $(0.500,0.300)$ & $(0.400,0.450)$ & $(0.544,0.230)$ & $(0.673,0.158)$ & $(0.876,0.079)$ \\
E4 & $(0.713,0.166)$ & $(0.619,0.211)$ & $(0.517,0.329)$ & $(0.500,0.300)$ & $(0.600,0.250)$ & $(0.696,0.137)$ & $(0.875,0.073)$ \\
E5 & $(0.576,0.243)$ & $(0.446,0.324)$ & $(0.285,0.478)$ & $(0.311,0.535)$ & $(0.500,0.300)$ & $(0.600,0.250)$ & $(0.788,0.104)$ \\
E6 & $(0.452,0.335)$ & $(0.311,0.478)$ & $(0.192,0.628)$ & $(0.168,0.652)$ & $(0.311,0.535)$ & $(0.500,0.300)$ & $(0.700,0.200)$ \\
E7 & $(0.228,0.634)$ & $(0.184,0.702)$ & $(0.075,0.874)$ & $(0.075,0.874)$ & $(0.122,0.767)$ & $(0.241,0.658)$ & $(0.500,0.300)$ \\
$\omega_{i}$ & $(0.0893,0.829)$ & $(0.109,0.802)$ & $(0.145,0.761)$ & $(0.151,0.752)$ & $(0.117,0.787)$ & $(0.088,0.827)$ & $(0.048,0.902)$ \\
$H\left(\omega_{i}\right)$ & 0.158 & 0.182 & 0.219 & 0.226 & 0.195 & 0.160 & 0.093 \\
$\sigma_{i}$ & 0.128 & 0.148 & 0.178 & 0.183 & 0.158 & 0.130 & 0.075 \\
Ranking & 6 & 4 & 2 & 1 & 3 & 7 & 7 \\
\hline
\end{tabular}

affecting the environmental risk of metro station engineering. The second- and third-largest weights of are E3 (adverse geomorphic conditions) and E5 (frequency of severe weather). The minimum weight (0.075) occurred for E7 (density of surrounding buildings).

According to Chinese code (standard for sustainability assessment of building project, JGJ/T 222-2011), the investigation results of the construction site of two stations are as follows. Chengdu is relatively close to the Longmenshan seismic belt in Sichuan, which has been active in recent years, with frequent seismic activity of varying degrees. Therefore, the frequency of natural disasters has the maximum weight. The Chengdu Metro Line 11 between Guandong Road Station and Huilong Avenue Station and between Diaoyuzui Station and Huilong Road Station is the high terrace, and the area between Huilong Avenue Station and Diaoyuzui Station has shallow, hilly, and variable terrain. These conditions make construction difficult. Thus, the adverse geomorphological conditions have great weight. Chengdu has a subtropical monsoon climate characterized by abundant rainfall and low sunshine hours, resulting in abundant groundwater. The area has abundant rainfall, and the flood season is May to September. The excavation of the foundation pit of this project occurred mostly in the rainy season. Continuous rainfall caused an increase in groundwater, affecting the surrounding environment and increasing the uncertainty of metro construction. The frequency of severe weather had a considerable impact on the Chengdu Metro Line 11. Density of surrounding buildings had a negligible influence, with the minimum weight. An appropriate construction plan can reduce the influence of the density of the surrounding buildings on the construction safety. These results indicate that the weighting results are in agreement with the actual conditions of the construction of the Chengdu Metro Line 11 station.

The following recommendations to achieve sustainability and manage environmental risks can be provided to the subway station construction workers and managers. The project managers should focus on the frequency of natural disasters (E4) and adverse geomorphological conditions (E3) when dealing with environmental risks. The majority of resources and energy should be focused on preventing natural disasters and reducing adverse geomorphic conditions around the construction site. During a natural disaster, construction should be stopped, and the building site should be reinforced to ensure construction safety. Before construction, the topography around the subway station should be surveyed, and an appropriate construction plan should be developed to reduce the influence of topographic conditions on the construction safety of the subway station. The construction company should formulate response plans, implement countermeasures, and, where possible, conduct test drills to minimize construction risks of the metro station. The frequency of severe weather (E5), adverse geological conditions (E2), the density of underground pipelines (E6), and the harsh hydrological conditions (E1) should be weighted moderately high, and the project manager should decide if implementation measures are required. The density 
of the surrounding buildings (E7) had the least impact on environmental risk; thus, the project manager should not invest many resources in E1 and E7.

\subsection{Results of the Environmental Risk Assessment of the} Subway Station Project. The scores of the environmental risk assessment indicators were used in (14) and (15) to obtain the results (Table 6).

Table 8 shows the results of combining the weights with the five environmental risk levels.

According to (13)-(15), the calculation result of fiveelement connection number of two stations can be calculated, as shown in Table 9. The risk level for $\lambda=0.6$ is determined by (16). The influence of the value of $\lambda$ on the calculation results will be discussed in Section 4.3.

Lushan Avenue Station has a risk level of V (extreme risk), and Huilong Road West Station has a risk level of III (moderate risk). According to Chinese code (Standard for sustainability assessment of building project, JGJ/T 2222011), the investigation results of the construction site of two stations are as follows. Lushan Avenue Station is located at the planned intersection of Zhongbai Avenue and Lushan Avenue. Zhongbai Avenue is oriented north-south. Wanan Town, rhyme community, and the Chengfeng Driving School are located in the northeast, Donglin Spring Phase II community is located in the northwest, Lushan International Community Yunxi Terrace is located in the southwest, and China Mobile is located in the southeast. The surrounding environment is complex, with a high building density. Surveys have shown that the station has complex hydrogeological conditions and high pipeline density. The evaluation results indicate that Lushan Avenue Station has an extreme risk, which is consistent with actual conditions. Extreme risk (V) means that the risk level is unacceptable, and the project manager must immediately stop construction and take measures to reduce the risk level to ensure the safety of project construction. Huilong Road West Station is close to the car park of Huilong of Line 5, which is oriented east-west on the south side of the planned Sancha Lake Expressway. The station has complex hydrogeological conditions, flat terrain, and few underground pipelines, and the actual conditions are consistent with the evaluation results of moderate risk. Moderate risk (III) indicates that the project manager needs to inspect the project and decide whether further risk response measures are required.

\subsection{Response Strategy of Subway Station Project Environ-} mental Risk. For the extreme risks of Lushan Avenue Station, we must attach great importance to and avoid them. Otherwise we must reduce the risks to an acceptable level at least at any cost. According to the actual situation of Lushan Avenue Station, in view of the poor hydrogeological conditions of the station, the stratum in the affected area should be reinforced to improve the antideformation ability of the stratum. Considering the high density of buildings around the excavation of the station, the most appropriate building reinforcement protection should be selected according to the structural form, building size, building quality, and expected uneven deformation of the existing buildings within the scope of the excavation measures.

The density of underground pipelines in this station is high, so the most suitable pipeline protection measures are comprehensively considered in combination with many factors such as site construction conditions, underground pipeline properties, and construction period. When risks are evaded or reduced to an acceptable range, the monitoring of construction site risks should be strengthened, and risk events caused by deformation of surrounding buildings and pipelines should be detected as early as possible, and a series of measures should be taken immediately to avoid risk events.

Although the landform condition of Huilong Road West Station is good, and there are no underground pipelines and surrounding buildings near the station, the hydrogeological condition of the station is poor, and the construction may cause large surface settlement and damage the retaining structure of foundation pit. Monitoring should be strengthened during construction, and monitoring should be focused on surface settlement and settlement speed. Determine different warning values in different construction stages and determine different monitoring frequencies at the same time. The foundation pit engineering is divided into before excavation, excavation, and after excavation. Each stage has its corresponding frequency and corresponding warning value. When the monitored data is abnormal, risk control measures should be taken according to the actual situation, and all parties of the company should be coordinated to deal with it to reduce the risk loss.

\section{Discussion}

Different methods were used to compare the environmental risk assessment results to demonstrate the superiority of the proposed method. The AHP and entropy power method were selected for weight calculation, and a fuzzy assessment, the grey correlation method, and the technique for order of preference by similarity to an ideal solution (TOPSIS) were used.

4.1. Comparison of Calculation Results Obtained from Different Weighting Methods. The comparison results of the importance of the evaluation indicators in Table 4 were transformed into a range of 1-9 for comparison with the AHP [35], as shown in Table 10. The indicator weights were $\omega=(0.046,0.094,0.266,0.368,0.156,0.071,0.021)$ and $C R=0.090<0.1$. Table 11 shows the weight calculation results obtained from the AHP.

The 20 experts were given questionnaires to score the seven indicators according to their importance from 1 to 9 , and the entropy weights of the indicators were evaluated according to the returned questionnaires. The weights of the corresponding indicators were $\omega=(0.034,0.141,0.104$, $0.267,0.245,0.186,0.022)$, as shown in Table 11 . The results of the weights for the density of underground pipelines and adverse geomorphological conditions obtained from the IFAHP and AHP differed significantly. The weight of the 
TABLE 8: The combination of the weights and the five environmental risk levels of the indicators.

\begin{tabular}{lcccccccrrr}
\hline \multirow{2}{*}{ Index } & \multicolumn{4}{c}{ Lushan avenue station } & \multicolumn{4}{c}{ Huilong road west station } \\
& $\mathrm{a}$ & $\mathrm{b} 1$ & $\mathrm{~b} 2$ & $\mathrm{~b} 3$ & $\mathrm{c}$ & $\mathrm{a}$ & $\mathrm{b} 1$ & $\mathrm{~b} 2$ & $\mathrm{~b} 3$ & $\mathrm{c}$ \\
\hline E1 & 0.0000 & 0.0000 & 0.0000 & 0.0448 & 0.0833 & 0.0000 & 0.0000 & 0.0000 & 0.1089 & 0.0192 \\
E2 & 0.0000 & 0.0000 & 0.0000 & 0.0000 & 0.1474 & 0.0000 & 0.0000 & 0.0000 & 0.0000 & 0.1474 \\
E3 & 0.0000 & 0.0000 & 0.0000 & 0.0266 & 0.1508 & 0.0887 & 0.0887 & 0.0000 & 0.0000 & 0.0000 \\
E4 & 0.0000 & 0.0514 & 0.1321 & 0.0000 & 0.0000 & 0.0000 & 0.0514 & 0.1321 & 0.0000 & 0.0000 \\
E5 & 0.0000 & 0.0949 & 0.0632 & 0.0000 & 0.0000 & 0.0000 & 0.0949 & 0.0632 & 0.0000 & 0.0000 \\
E6 & 0.0000 & 0.1297 & 0.0000 & 0.0000 & 0.0000 & 0.1297 & 0.0000 & 0.0000 & 0.0000 & 0.0000 \\
E7 & 0.0000 & 0.0000 & 0.0000 & 0.0379 & 0.0379 & 0.0758 & 0.0000 & 0.0000 & 0.0000 & 0.0000 \\
$f_{k}$ & 0.0000 & 0.2759 & 0.1953 & 0.1094 & 0.4194 & 0.2943 & 0.2349 & 0.1953 & 0.1089 & 0.1666 \\
\hline
\end{tabular}

TABLE 9: The environmental risk levels of the two stations.

\begin{tabular}{lcccccc}
\hline Case objects & $f_{1}$ & $f_{2}$ & $f_{3}$ & $f_{4}$ & $f_{5}$ & Level \\
\hline $\begin{array}{l}\text { Lushan avenue } \\
\text { station }\end{array}$ & 0.0000 & 0.2759 & 0.1953 & 0.1094 & 0.4194 & $\mathrm{~V}$ \\
$\begin{array}{l}\text { Huilong road } \\
\text { west station }\end{array}$ & 0.2943 & 0.2349 & 0.1953 & 0.1089 & 0.1666 & III \\
\hline
\end{tabular}

density of underground pipelines was 0.186 (third place). The weight of adverse geomorphological conditions was 0.104 , ranking fifth.

Therefore, the results show that the IFAHP accurately describes the opinions of decision-makers if incomplete information is available and considers the certainty and uncertainty of environmental risk in subway station construction and the hesitation of the experts in the weight calculation.

A comparison of the results of the weights between the IFAHP and the AHP shows that the order of importance of the indicators has not changed, and only the weights have changed. The AHP failed to pass the one-time test, unlike the IFAHP. In the AHP, a new test had to be performed for the decision matrix that failed the consistency test, whereas the IFAHP adjusted the matrix by setting parameters, which did not require the participation of decision-makers and was faster and more accurate than the AHP.

The environmental survey showed that the area around the station of Chengdu Metro Line 11 is mostly open, and the density of underground pipelines at most of the stations is relatively low. The area of the Chengdu Metro Line 11 contains terraces and shallow hills, and the topography and geomorphology are relatively complex. Therefore, there is a significant discrepancy between the weight ranking obtained from the entropy weighting method and actual conditions.

Therefore, the results show that the IFAHP accurately describes the opinions of decision-makers if incomplete information is available and considers the certainty and uncertainty of environmental risk in subway station construction and the hesitation of the experts in the weight calculation.

4.2. Comparison of the Results Obtained from Different Evaluation Methods. We used the weighting results of the IFAHP and the results of the scores of the qualitative indicators and quantitative indicators to conduct an environmental risk evaluation of Lushan Avenue Station and Huilong Road West Station using a fuzzy evaluation. The evaluation result for Lushan Avenue Station was [0.000, $0.288,0.183,0.301,0.228]$. The risk level of Lushan Avenue Station was IV. The evaluation result of the Huilong Road West Station was $[0.205,0.336,0.183,0.128,0.148]$, and the risk level of the Huilong Road West Station was II. These results demonstrate that the two evaluation models provide similar results for the environmental risks of the subway stations.

The grey correlation degree is used to evaluate the environmental risks of subway stations. Based on the average of the risk index scores of Lushan Avenue Station and Huilong Road West Station, the grey correlations of the two stations are derived. The grey correlation degree of Lushan Avenue Station is 0.4156 (risk level IV), and the grey correlation degree of Huilong Road West Station is 0.6514 (risk level II). The evaluation results are similar to those of the SPA. The grey relational analysis prevents the ambiguity of the indicators, but it requires the determination of the optimal value of each indicator, which is subjective and challenging. The SPA does not have the disadvantages of grey relational analysis and has better reliability.

TOPSIS is used to evaluate the environmental risks of subway stations. The relative closeness for Lushan Avenue Station is 0.4515 (risk level IV). The relative closeness of Huilong Road West Station is 0.5700 (risk level III). The evaluation results are consistent with those obtained from the other evaluation methods. TOPSIS is a straightforward method but, similar to the grey relational analysis, it is difficult to determine the optimal value of the indices. When the index values of two indicators are the same for the best and worst scheme, accurate results cannot be obtained.

The extension matter-element method is used to evaluate the environmental risks of subway station projects. According to the classification standards of the risk factors of each risk factor and the average number of the scores of each index, the classic domain matter element, the node domain matter element, and the pending evaluation of the evaluation model are determined. Matter element calculates the correlation function value of each evaluation index with respect to the evaluation grade and combines the weight calculation result of IFAHP to calculate the correlation degree of the evaluation grade between Lushan Avenue Station and Huilong Road West Station, as shown in the table. 
TABLE 10: Correspondence between the 1-9 scale and the intuitionistic fuzzy values.

\begin{tabular}{lccccccccc}
\hline Intuitive ambiguity & $(0.90,0.10)$ & $(0.80,0.15)$ & $(0.70,0.20)$ & $(0.60,0.25)$ & $(0.50,0.30)$ & $(0.40,0.45)$ & $(0.30,0.60)$ & $(0.20,0.75)$ & $(0.10,0.90)$ \\
\hline $1-9$ scale & 9 & 7 & 5 & 3 & 1 & $1 / 3$ & $1 / 5$ & $1 / 7$ & $1 / 9$ \\
\hline
\end{tabular}

TABLE 11: Calculation results of different weighting methods.

\begin{tabular}{|c|c|c|c|c|c|c|}
\hline \multirow{2}{*}{ Index } & \multicolumn{2}{|c|}{ IFAHP } & \multicolumn{2}{|c|}{ AHP } & \multicolumn{2}{|c|}{ Entropy weighting method } \\
\hline & Weight & Order & Weight & Order & Weight & Order \\
\hline $\mathrm{E} 1$ & 0.128 & 6 & 0.046 & 6 & 0.034 & 6 \\
\hline E2 & 0.148 & 4 & 0.094 & 4 & 0.141 & 4 \\
\hline E3 & 0.178 & 2 & 0.266 & 2 & 0.104 & 5 \\
\hline $\mathrm{E} 4$ & 0.183 & 1 & 0.368 & 1 & 0.267 & 1 \\
\hline E5 & 0.158 & 3 & 0.156 & 3 & 0.245 & 2 \\
\hline E6 & 0.130 & 5 & 0.071 & 5 & 0.186 & 3 \\
\hline E7 & 0.075 & 7 & 0.021 & 7 & 0.022 & 7 \\
\hline
\end{tabular}

According to the principle of maximum subordination, the environmental risk levels of the two subway station projects are determined: $\max \left\{k_{\mathrm{I}}(L) ; k_{\mathrm{II}}(L) ; k_{\mathrm{III}}(L) ; k_{\mathrm{IV}}\right.$ $\left.(L) ; k_{\mathrm{V}}(L)\right\}=k_{\mathrm{V}}(L)=0.0605$, that is, the risk level of Lushan Avenue Station is V; $\max \left\{k_{\mathrm{I}}(H) ; k_{\mathrm{II}}(H) ; k_{\mathrm{III}}(H)\right.$; $\left.k_{\mathrm{IV}}(H) ; k_{\mathrm{V}}(H)\right\}=k_{\mathrm{III}}(H)=0.2734$, that is, the risk level of Huilong Road West Station is III.

The evaluation results of each evaluation method are shown in Table 12.

When performing fuzzy comprehensive evaluation on Lushan Avenue Station, the risk levels of II and IV are relatively close, and the weighting of some indicators has a considerable impact on the evaluation results, resulting in inaccuracies. The SPA provides more accurate results because it analyzes the interaction between certainty and uncertainty from a systems perspective.

The grey correlation model effectively resolves the ambiguity of indicators, but it is necessary to determine the optimal value of each indicator currently, which is too subjective, and it is difficult to determine the optimal value of some indicators in the calculation process. In the process of calculating the grey correlation degree in this paper, because the data of $+\infty$ appears in the evaluation standard, the calculation result has a certain deviation. The data analysis of the generated deviation shows that when parameter adjustments are made to the optimal value of the index, a slight numerical change can make a large change in the level interval. It can be seen that in the evaluation process, once an overly subjective expert opinion appears, it can have an irreversible impact on the final result. And the overall degree of relevance is obtained by adding the correlation coefficients, and the overall degree of relevance is determined by the large correlation coefficient, which causes partial relevance tendencies and biases the analysis results. SPA does not need to determine the optimal value of indicators, which avoids the disadvantages of grey correlation degree. At the same time, considering the fuzziness of grade standard boundary, it does not need to determine the optimal value of each indicator, which avoids the difficult problem of directly determining the difference uncertainty (component) coefficient in the correlation degree and has good reliability and operability.

TOPSIS is to construct a two-dimensional data space of the distance between the evaluation index and the optimal solution and the worst solution by seeking the optimal solution and the worst solution in each index and, on this basis, the evaluation index and the optimal solution. We compare with the worst solution. If it is the closest to the optimal solution and the farthest away from the worst solution, then the plan is the best plan among the plans to be evaluated. Conversely, if it is the closest to the worst solution and the farthest away from the optimal solution, then the plan is the worst plan among the plans to be evaluated. When using this method to evaluate the subway station environment, $+\infty$ also appears in the worst solution, which leads to a certain error between the calculation result and the actual situation. The most prominent feature of TOPSIS algorithm lies in the forward module calculation of indicators. The uncertain indicators of risk factors have been analyzed and quantified in the projects relied on in this paper, and there are inaccuracies in the quantification of some natural disaster indicators; it is impossible to describe the impact of indicators perfectly. Therefore, TOPSIS is not suitable for risk assessment of this project.

When the extension matter element is used for evaluation, the distance function in the matter-element extension does not take into account the interval and the relative position relationship between the midpoint of the interval and the variable. SPA adopts interval segmentation, which can avoid this problem well. At the same time, the degree of relevance is the basis for determining the level of the evaluation object. When the relevance of each index for each evaluation level is negative, according to the meaning of the degree of relevance, it is impossible to judge the evaluation 
TABLE 12: Evaluation results of different evaluation methods.

\begin{tabular}{lccccc}
\hline Station & SPA & Fuzzy comprehensive evaluation & Grey relational degree & TOPSIS & Extension matter element \\
\hline Lushan avenue station & V & IV & IV & IV & V \\
Huilong road west station & III & II & II & II & III \\
\hline
\end{tabular}

TABle 13: Calculation results for different values of $\lambda$.

\begin{tabular}{lcc}
\hline Value of $\lambda$ & Lushan avenue station & Huilong road west station \\
\hline 0.5 & IV & II \\
0.55 & IV & III \\
0.6 & V & III \\
0.65 & V & III \\
0.7 & V & III \\
\hline
\end{tabular}

level of each indicator. When using set pair analysis to calculate the connection components of each indicator, normalizing the indicators can avoid the occurrence of this situation.

4.3. Comparison of the Results of Different Lambda Calculations. Different values of $\lambda$ indicate different attitudes of the decision-makers; the larger the value of $\lambda$ is, the more conservative the results are. In this study, the value of lambda is 0.6 . In previous studies, the value of $\lambda$ was usually 0.5-0.7; thus, we calculate the environmental risk levels of Lushan Avenue Station and Huilong Road West Station in this range of $\lambda$.

$\lambda$ represents the probability of the analysis results being in a certain range and the degree of confidence in the decision. A small value of $\lambda$ is unlikely. Table 13 shows the confidence level for the different risk levels. If the confidence level is very low, the risk level is low, and the probability of an evaluation error is high. If the confidence level is very high and the risk level is high, the probability of an evaluation error is low, but the practical significance is small. When $\lambda=0.5$, relatively low risk levels are obtained; the risk level of Lushan Avenue Station is IV, and the risk level of Huilong Road West Station is II. When $\lambda=0.7$, higher risk levels are obtained; that is, the risk level of Lushan Avenue Station is V, and that of Huilong Road West Station is III. As the risk attitude shifts from low to high, the risk level increases. This calculation is consistent with the results of previous research [46-48].

\section{Conclusions}

To achieve sustainability of subway station construction projects, this paper proposes an environmental risk assessment of subway station engineering based on the IFAHP and the SPA. We established an initial and general index system for an environmental risk assessment of subway station construction and used 19 index factors. A typical subway station project was used as an example, and the rough set method was used to reduce the number of indices, resulting in an index system for an environmental risk assessment of subway station construction using seven indicators. The IFAHP was used to calculate the index weights to avoid having to obtain expert opinions again when the consistency test failed, as is required in the subjective AHP method. The fuzziness of expert decisions in the weight calculation was considered, and the disadvantage of poor interpretability of the calculation results in objective weight calculation methods, such as the entropy weight method, was avoided. The SPA was used to evaluate the risk level since it considers certainty and uncertainty as an integrated system and describes them as identity, discrepancy, and contrary relationships. The evaluation results are also compared with fuzzy comprehensive evaluation, grey relational degree, TOPSIS, and matter-element extension method to illustrate the superiority of the proposed method. The results of the case study showed that the dominant environmental risks of subway station construction included the frequency of natural disasters and adverse geomorphological conditions, and the majority of resources and energy should focus on these types of disasters. The risk level of Lushan Avenue Station was extreme, and the project manager should immediately stop construction and take measures to reduce the risk level. The risk level of Huilong Road West Station was moderate, and the project manager should decide whether further risk response measures are necessary. The proposed method provided better performance than the traditional AHP, the entropy weight method, the fuzzy evaluation, the grey correlation analysis, and the TOPSIS.

Although the IFAHP and the SPA provided satisfactory results for the environmental risk assessment of subway station projects, this study has the following limitations. (1) The index system for the environmental risk assessment of metro station projects was based on 38 typical metro station projects in China. The index system and risk assessment results will likely be different for different metro stations. (2) The weight results did not provide an accurate and complete representation of the opinions of different experts. A future study will focus on a unified and universal environmental risk assessment index system, or fully.

\section{Data Availability}

The case analysis data used to support the findings of this study are available from the corresponding author upon request.

\section{Conflicts of Interest}

The authors declare that there are no conflicts of interest regarding the publication of this paper.

\section{Acknowledgments}

This study was supported by the Science and Technology Project of Wuhan Urban and Rural Construction Bureau, China (201943). 


\section{References}

[1] Y.-S. Shen, P. Wang, M.-P. Li, and Q.-W. Mei, "Application of subway foundation pit engineering risk assessment: a case study of Qingdao rock area, China," KSCE Journal of Civil Engineering, vol. 23, no. 11, pp. 4621-4630, 2019.

[2] M. Wang, "The evaluation system of green construction in Qindao metro project," Journal of Ocean University of China (Natural Science Edition), vol. 45, no. 1, pp. 90-94+101, 2015.

[3] J. C. Wang and F. Zhang, "Risk assessment of the deep foundation pit based on the entropy weight and 2-dimensional cloud model," Journal of Safety and Environment, vol. 18, no. 3, pp. 849-853, 2018.

[4] G. H. Zhang, C. T. Wang, Y. Y. Jiao et al., "Collapse risk analysis of deep foundation pits in metro stations using a fuzzy Bayesian betwork and a fuzzy AHP," Mathematical Problems in Engineering, vol. 2020, Article ID 4214379, 18 pages, 2020.

[5] H. Z. Pan, J. Guo, Z. H. Wan et al., "Research on coupling degree model of safety risk system for tunnel construction in subway shield zone," Mathematical Problems in Engineering, vol. 2019, Article ID 5783938, 19 pages, 2019.

[6] Y. J. Wu, A. X. Chen, and Z. G. Zhu, "Analysis on prevention measures and geology and environment risks at Fangshan line of Beijing subway," Chinese Journal of Underground Space and Engineering, vol. 10, no. 3, pp. 721-726+738, 2014.

[7] D. Hu and J. C. Duan, "Risk source analysis and grade division of subway tunnel undercrossing the existing highway subjected to the complicated geological environment," in Proceedings of the International Conference on Power Engineering and Energy, Environment (PEEE), pp. 680-684, Shanghai, China, June 2016.

[8] X. K. Niu, D. L. Zhang, X. Y. Gao, and J. Su, "Safety risk assessment of paralled and closely-attached metro station under-passing existing subway tunnel," Journal of Beijing Jiaotong University, vol. 42, no. 3, pp. 95-102, 2018.

[9] Z. H. Luo, L. Zeng, H. Z. Pan et al., "Research on construction safety risk assessment of new subway station close-attached undercrossing the existing operating station," Mathematical Problems in Engineering, vol. 2019, Article ID 3215219, 20 pages, 2019.

[10] M. Heydari and K. K. Lai, "A study on risk and expense evaluation of agility supply management of machinery," Discrete Dynamics in Nature and Society, vol. 2020, Article ID 7030642, 19 pages, 2020.

[11] K. Kuru and D. Artan, "A canvas model for risk assessment and performance estimation in public-private partnerships," International Journal of Construction Management, vol. 20, no. 6, pp. 704-719, 2020.

[12] A. Razaque, F. Amsaad, S. Hariri, M. Almasri, S. S. Rizvi, and M. B. H. Frej, "Enhanced grey risk assessment model for support of cloud service provider," IEEE Access, vol. 8, pp. 80812-80826, 2020.

[13] Y. Xue, Z. Li, D. Qiu et al., "Prediction model for subway tunnel collapse risk based on delphi-ideal point method and geological forecast," Soil Mechanics and Foundation Engineering, vol. 56, no. 3, pp. 191-199, 2019.

[14] S. Bajic, D. Bajic, B. Gluscevic, and V. R. Vakanjac, "Application of fuzzy analytic hierarchy process to underground mining method selection," Symmetry-Basel, vol. 12, no. 2, p. 192, 2020.

[15] F. R. Lima and L. C. R. Carpinetti, "Dealing with the problem of null weights and scores in fuzzy analytic hierarchy process," Soft Computing, vol. 24, no. 13, pp. 9557-9573, 2020.
[16] C. Shan, J. Yang, Z. Dong, D. Huang, and H. Wang, "Study on river health assessment weight calculation," Polish Journal of Environmental Studies, vol. 29, no. 2, pp. 1839-1848, 2020.

[17] R. Ohta, V. A. P. Salomon, and M. B. Silva, "Classical, fuzzy, hesitant fuzzy and intuitionistic fuzzy analytic hierarchy processes applied to industrial maintenance management," Journal of Intelligent \& Fuzzy Systems, vol. 38, no. 1, pp. 601-608, 2020.

[18] X. Yu, D. Zheng, and L. Zhou, "Credit risk analysis of electricity retailers based on cloud model and intuitionistic fuzzy analytic hierarchy process," International Journal of Energy Research, vol. 45, no. 3, pp. 4285-4302, 2021.

[19] J. J. Xu, L. J. Yu, and R. Gupta, "Evaluating the performance of the government venture capital guiding fund using the intuitionistic fuzzy analytic hierarchy process," Sustainability, vol. 12 , no. 17 , p. $6908,2020$.

[20] Z. Z. Wang and C. Chen, "Fuzzy comprehensive Bayesian network-based safety risk assessment for metro construction projects," Tunnelling and Underground Space Technology, vol. 70, pp. 330-342, 2017.

[21] L. Wu, H. Bai, C. Yuan, and C. Xu, "FANPCE technique for risk assessment on subway station construction," Journal of Civil Engineering and Management, vol. 25, no. 6, pp. 599616, 2019.

[22] Y. Qin, Z. Zhang, X. Liu, M. Li, and L. Kou, "Dynamic risk assessment of metro station with interval type-2 fuzzy set and TOPSIS method," Journal of Intelligent \& Fuzzy Systems, vol. 29, no. 1, pp. 93-106, 2015.

[23] G. Huang, S. Sun, and D. Zhang, "Safety evaluation of construction based on the improved AHP-grey model," Wireless Personal Communications, vol. 103, no. 1, pp. 209-219, 2018.

[24] G. Sun, X. Guan, X. Yi, and Z. Zhou, "Grey relational analysis between hesitant fuzzy sets with applications to pattern recognition," Expert Systems with Applications, vol. 92, pp. 521-532, 2018.

[25] X. F. Chen and W. T. Chen, "Application of set pair analysis theory in safety pre-evaluation of blasting engineering," Journal of Safety Science and Technology, vol. 13, no. 1, pp. 146-150, 2017.

[26] Q. Wang, C. M. Yang, L. Tian et al., "Safety risk assessment of heritage buildings in metro construction based on SPA theory: a case study in Zhengzhou, China," Heritage Science, vol. 8, no. 1, p. 100, 2020.

[27] H. Y. Yu, C. Liang, P. Li et al., "Evaluation of waterlogging risk in an urban subway station," Advances in Civil Engineering, vol. 2019, Article ID 5393171, 12 pages, 2019.

[28] D. P. Du and G. Z. Ying, "Risk assessment of subway construction based on AHP and set pair analysis," Journal of Hefei University of Technology (Natural Science), vol. 37, no. 8, pp. 962-965, 2014.

[29] E. Forcael, H. Morales, D. Agdas, C. León, and C. Leon, "Risk identification in the chilean tunneling industry," Engineering Management Journal, vol. 30, no. 3, pp. 203-215, 2018.

[30] W. B. You, J. B. Wang, W. Zhang, F. M. Liu, and D. Y. Yang, "Construction risk assessment of deep foundation pit in metro station based on G-COWA method," in Proceedings of the 2018 2nd International Workshop on Renewable Energy and Development (IWRED 2018), Guilin China, April 2018.

[31] G. F. Wang, H. M. Lyu, J. S. L. Shen et al., "Evaluation of environmental risk due to metro system construction in Jinan, China," International Journal of Environmental Research and Public Health, vol. 14, no. 10, p. 1114, 2017.

[32] G. Z. Ying, P. C. Wang, D. Y. Zhu et al., "Risk assessment of subway construction based on fuzzy comprehensive 
evaluation model," Chinese Journal of Underground Space and Engineering, vol. 12, no. 2, pp. 539-545, 2016.

[33] Q. Z. Yu, L. Y. Ding, C. Zhou, and H. B. Luo, "Analysis of factors influencing safety management for metro construction in China," Accident Analysis \& Prevention, vol. 68, pp. 131-138, 2014.

[34] J. Chun and H. K. Lee, "Developing a service evaluation index for Internet addiction through the Delphi method," International Journal of Mental Health Promotion, vol. 19, no. 4, pp. 224-238, 2017.

[35] L. Dou, A.-T. Yin, M. Hao, and J. Lu, "An evaluation system for financial compensation in traditional Chinese medicine services," Complementary Therapies in Medicine, vol. 23, no. 5, pp. 637-643, 2015.

[36] N. Bjorngrim, O. Hagman, and X. D. Wang, "Multivariate screening of the weather effect on timber bridge movements," Bioresources, vol. 11, no. 4, pp. 8890-8899, 2016.

[37] Y. Wang and S. Van Aelst, "Robust variable screening for regression using factor profiling," Statistical Analysis and Data Mining: The ASA Data Science Journal, vol. 12, no. 2, pp. 70-87, 2019.

[38] B. Liu, F. Wu, X. Dai, F. Liu, and B. Mi, "Variations of cadmium accumulation and translocation in different pakchoi cultivars and screening for cd-pollution-safe cultivars using cluster analysis," Polish Journal of Environmental Studies, vol. 28, no. 4, pp. 2215-2222, 2019.

[39] M. Inuiguchi, "Generalizations of rough sets and rule extraction," Transactions on Rough Sets I, vol. 3100, pp. 96-119, 2004.

[40] K. T. Atanassov, "Intuitionistic fuzzy sets," Fuzzy Sets and Systems, vol. 20, no. 1, pp. 87-96, 1986.

[41] L. A. Zadeh, "Fuzzy sets," Information and Control, vol. 8, no. 3, pp. 338-353, 1965.

[42] Z. S. Xu and H. C. Liao, "Intuitionistic fuzzy analytic hierarchy process," IEEE Transactions on Fuzzy Systems, vol. 22, no. 4, pp. 746-761, 2014.

[43] Y. Huang, W. Wu, and S. Yang, "Sustainable development of green building based on intuitionistic fuzzy analytic hierarchy process," Applied Ecology and Environmental Research, vol. 17, no. 1, pp. 1093-1108, 2019.

[44] K. Q. Zhao, "Set pair analysis and its preliminary application," Discovery of Nature, vol. 13, no. 1, pp. 67-72, 1994.

[45] W. Wang, J. Jin, J. Ding, and Y. Li, "A new approach to water resources system assessment-set pair analysis method," Science in China Series E: Technological Sciences, vol. 52, no. 10, pp. 3017-3023, 2009.

[46] H. Wu, J. W. Wang, S. Liu, and T. Yang, "Research on decision-making of emergency plan for waterlogging disaster in subway station project based on linguistic intuitionistic fuzzy set and TOPSIS," Mathematical Biosciences and Engineering, vol. 17, no. 5, pp. 4825-4851, 2020.

[47] J. Wu and Y. Liu, "An approach for multiple attribute group decision making problems with interval-valued intuitionistic trapezoidal fuzzy numbers," Computers \& Industrial Engineering, vol. 66, no. 2, pp. 311-324, 2013.

[48] J. Wu and F. Chiclana, "A risk attitudinal ranking method for interval-valued intuitionistic fuzzy numbers based on novel attitudinal expected score and accuracy functions," Applied Soft Computing, vol. 22, pp. 272-286, 2014. 